\title{
Make life choices with confidence and security
}

Future-focused financial planning business Wealthwide officially launched to the UK dental profession on 15 July.

Wealthwide helps dentists see their full financial picture so they can get more out of life. It is the vision of Managing Director Thomas Dickson (pictured), who has specialised in working with dentists for over 20 years and decided to rebrand from Essential Money to Wealthwide.

Wealthwide's focus is to help dental professionals see the full extent of their financial picture. This allows them to plan to do the things they really want to in life, with security and peace of mind swapping long hours for long weekends and overtime for family time.

Wealthwide's planning services enable dentists to understand their financial options so that they can make life choices with confidence and security.

Wealthwide planning can help answer all sorts of tricky questions, such as: when can I afford to stop working? What rate of investment return do I need to do all the things I hope to do? Can I afford to sell my practice? Will downsizing my home in the future release enough funds to support my retirement? Will I still be able to live comfortably if I give money to my children?

The lockdowns and change in working practices over the last 18 months have led many of Thomas' clients to reconsider their position and longer-term future. The rebrand to Wealthwide makes it absolutely crystal clear what the company can do for clients. Wealthwide helps dentists to question what they really want from life, to fully understand their financial position and make the big life decisions based on hard facts. Financial planning helps Wealthwide's clients to create the work-life balance they deserve.

The pandemic has had a significant financial impact on the dental profession.

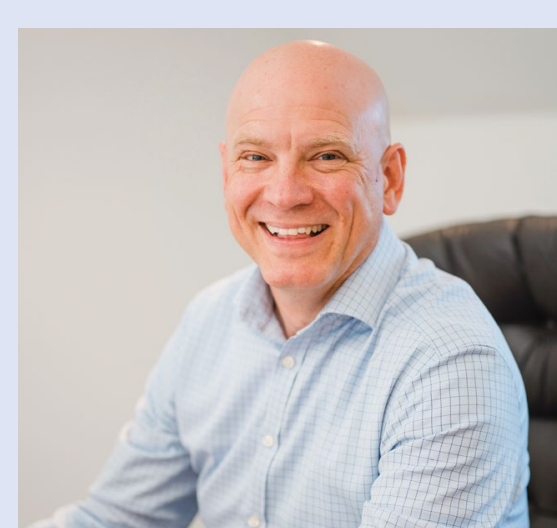

Requests from dental students, dentists and their families seeking help from the BDA Benevolent Fund increased $120 \%$ in 2020 compared to the previous year. This coincided with a reduction in donations from dentists both through individual giving and fundraising events. In recognition of this, Wealthwide is pledging $£ 5,000$ to the charity.

For more information about Wealthwide, visit www.wealthwide.co.uk.

\section{Property compliance and health and safety}

Henry Schein Business Solutions specialises in finding partner companies which can help dentists run their practices efficiently and smoothly, whilst they concentrate on providing excellent patient care.

Property compliance and abiding by health and safety regulations are two aspects of dental practice management that can be a real burden for busy owners and managers. There's a great deal to stay on top of, including keeping important documents up-to-date and stored securely, carrying out mandatory risk assessments, ensuring staff are adequately trained and making sure that the practice is adopting systems and processes in line with changing laws and regulations.

Crysp is a specialist online compliance platform run by knowledgeable and experienced compliance experts. Key features of the platform include a Compliance Monitor which ensures you never miss critical statutory inspections or any other responsibilities. A Document Management section keeps all your documents in a safe and secure location and digital forms to replace laborious paper versions.

Expertise is always on hand from advisory teams specialising in Fire Risk Assessments, Workplace Health \& Safety Inspections and COVID-19 Risk Assessments, as well as general help and support on all aspects of compliance, both in person and online. The platform also hosts over 100 e-learning modules.

As part of Henry Schein Business Solutions, Crysp offers Henry Schein customers market-leading preferential rates which are not available anywhere else.

Full details of the services available to help dental practices grow and prosper can be found at hsbusinesssolutions. co.uk or alternatively speak to your local Henry Schein representative.

A series of webinars featuring Business Solutions partners is running through the year. Sign up at https:// www.hsbusinesssolutions.co.uk/ webinars-and-business-news.

Recordings of previous webinars can be viewed at: https://www.gotostage. com/channel/hsbusinesssolutions. www.henryschein.co.uk

\section{Learning and networking}

The 17th BACD Annual Conference is set to meet even the highest expectations, with a dynamic lecture programme and a first-class speaker line-up.

It will also be a fantastic opportunity to finally catch up with friends and colleagues from across the profession. After so much time apart, the social aspect will be just as important as the learning at this event.

For the legendary Gala Dinner on Friday night, you are even invited to a Night At The Museum - so you can enjoy drinks and a gala meal, alongside lots of entertainment, dancing and fun at the first BACD black-tie event of the season! With limited availability, book soon to avoid disappointment.

One thing is for certain - the BACD Annual Conference 2021 will offer learning and networking galore!

The BACD 17th Annual Conference, 'Seeing Is Believing', will be held on 11-13 November 2021 at The EICC, Edinburgh, Scotland.

For further enquiries about the British Academy of Cosmetic Dentistry, visit www.bacd.com. 